\title{
MANAGING COORDINATION IN MULTITEAM SYSTEMS: INTEGRATING MICRO AND MACRO PERSPECTIVES
}

\author{
THOMAS A. DE VRIES \\ University of Groningen \\ JOHN R. HOLLENBECK \\ Michigan State University \\ ROBERT B. DAVISON \\ University of Kansas \\ FRANK WALTER \\ Justus Liebig University Giessen \\ GERBEN S. VAN DER VEGT \\ University of Groningen
}

\begin{abstract}
Multiteam systems (i.e., teams of teams) are frequently used to deal with complex and demanding challenges that require several teams' joint efforts. However, achieving effective horizontal coordination across component teams in these systems remains difficult. Using insights from organizational behavior research, we argue that horizontal coordination between component teams can benefit if a multiteam system is composed of generalist members who are acquainted with the multiple functions present in the overall system (i.e., high intrapersonal functional diversity [IFD]). At the same time, however, such IFD may have detrimental side effects because generalists' broad focus may distract them from high-impact, specialized activities (i.e., aspirational behavior). Building on insights from organization theory, we propose that coordination across a multiteam system's hierarchical layers (i.e., vertical coordinated action between a team tasked with system-wide integration and task-specialized component teams) is critical for reaping IFD's benefits while avoiding its costs. These notions are supported in a sample of 236 14-person multiteam systems engaged in a realistic decision-making simulation. Our findings illustrate how combining insights from organizational behavior and organization theory can advance academic knowledge on multiteam systems and offer practical solutions for managing such systems.
\end{abstract}

Many critical tasks in business and society are beyond the capacity of single individuals or even single teams (DeChurch \& Zaccaro, 2010). For example, large-scale transportation networks, military

We gratefully acknowledge the generous support provided by the faculty, staff, and students of the United States Air Force (USAF) Squadron Officer College, Maxwell Air Force Base, Montgomery, Alabama. In particular, we thank Gen. Donald Cook, USAF, Retired; Col. Michael Tanous, USAF; Lt. Col. Stephen Harmon, USAF; Maj. Caroline Knutson-Vacarro, USAF, Retired; Maj. Kenneth Hanson, USAF, Retired; and Drs. Filomeno Arenas and Matthew Stafford. Special thanks go to Dr. Hank Dasinger for his vision and leadership managing the multiteam system that was required to accomplish this research. operations (Goodwin, Essens, \& Smith, 2012), emergency responses (DeChurch \& Mathieu, 2009), and new product developments (Hoegl, Weinkauf, \& Gemuenden, 2004) typically require coordinated actions of two or more teams, each of which have distinct areas of expertise (Mathieu, Marks, \& Zaccaro, 2001). These "multiteam systems" bring together "a complex variety of skills, knowledge, and functions" in adaptive structures that are especially suited to managing highly complex environments (Zaccaro, Marks, \& DeChurch, 2012: 12). They comprise a greater number of members and are structurally more complex than standalone teams (with distinct component teams as an additional layer), but they are smaller, more agile, and less bureaucratic than traditional multi-unit organizations (e.g., 
corporate divisions) (Davison, Hollenbeck, Barnes, Sleesman, \& Ilgen, 2012).

In order to function effectively, multiteam systems need to combine the efforts of the component teams responsible for operational task execution (Ford \& Schmidt, 2000; Mathieu et al., 2001; Zaccaro et al., 2012). Such horizontal coordination represents the extent to which component teams from the same hierarchical level align and synchronize their activities with each other (Lanaj, Hollenbeck, Ilgen, Barnes, \& Harmon, 2013; Marks, DeChurch, Mathieu, Panzer, \& Alonso, 2005). Effective horizontal coordination enables multiteam systems to synthesize component teams' distinct contributions and utilize these teams' complete range of specialized resources (DeChurch \& Mathieu, 2009; Marrone, 2010; Smith, Carroll, \& Ashford, 1995). Regrettably, however, horizontal coordination is often difficult to achieve due to multiteam systems' sheer size (Browning, 1998; Davison et al., 2012) and due to misunderstandings that can arise from differences in component teams' languages, routines, and thought-worlds (Zaccaro et al., 2012). Indeed, it appears notoriously difficult to effectively manage multiteam systems, and many of the documented performance breakdowns within such systems have been attributed to ineffective horizontal coordination (DeChurch \& Zaccaro, 2010). Prime examples include the delayed emergency response following Hurricane Katrina in 2005 (DeChurch \& Mathieu, 2009) and the loss of the Mars climate orbiter in 1999 (Postrel, 2002).

Two distinct research perspectives have generated insights into how to promote horizontal coordination. The dominant line of reasoning, in this respect, derives from a micro-level organizational behavior (OB) tradition. It focuses on providing teams with the capacity for realizing horizontal coordination in a bottom-up manner (Crichton \& Flin, 2004; Ford \& Schmidt, 2000). An important strategy that has emerged from this line of inquiry is to compose or develop teams with broad functional generalists, instead of narrow specialists (Joshi, Pandey, \& Han, 2009; Park, Lim, \& Birnbaum-More, 2009). Studies in standalone, cross-functional teams, for example, have shown that intrapersonal functional diversity (IFD), defined as team members' average breadth of functional experience (Bunderson \& Sutcliffe, 2002), improves members' collective understanding of each other's specialized contexts and constraints (Cannella, Park, \& Lee, 2008; Park et al., 2009). Similarly, research on cross-training suggests that rotation through functionally distinct positions broadens members' knowledge of shared tasks, equipment, and functions (Cannon-Bowers, Salas, Blickensderfer, \& Bowers, 1998; Marks, Sabella, Burke, \& Zaccaro, 2002). Building on this logic, high IFD seems likely to facilitate horizontal coordination between component teams and promote multiteam system performance (Ford \& Schmidt, 2000).

There is an important caveat to this conclusion, however, in that empirical research relating IFD to multiteam system performance is lacking. In addition, research in related areas has not consistently established IFD's benefits for larger organizational units with multiple (sub)groups (Leenders \& Wierenga, 2002; Maltz \& Kohli, 2000). In fact, increasing IFD may have the unintended side effect of limiting the depth of members' functional experiences and diminishing their task focus (Hatvany \& Pucik, 1981; Raskas \& Hambrick, 1992). Steps taken to develop broad functional experience may hinder members' specialization (Cannella et al., 2008; Tesluk \& Jacobs, 1998), in particular, because time, talent, and training budgets are all limited resources. This may pose important problems for multiteam systems, as members lacking deep, comprehensive experience in a specific work area have a tendency to avoid, rather than proactively solve, difficult problems associated with the respective area (Jans \& Frazer-Jans, 2004; Postrel, 2002). Thus, IFD's potential benefits for horizontal coordination may come at the cost of decreased aspirational behavior (i.e., a multiteam system's engagement in complex, specialized activities that push performance boundaries [Lanaj et al., 2013]).

A second, independent research perspective may reconcile these countervailing effects of IFD. Grounded in macro-level organization theory (OT) (e.g., Galbraith, 1994; Lawrence \& Lorsch, 1967), this perspective focuses on formal, top-down integration mechanisms that can promote multiteam system performance (Browning, 1998; Davison et al., 2012). Research in this tradition has found, in particular, that a central group of formal boundary spanners with system-wide integrative leadership responsibilities (Sherman \& Keller, 2011) can support component teams through vertical coordinated action (i.e., "coordination that takes place between report-to and direct reporting actors across organizational levels whose breadth of scope and authority differ" [Davison et al., 2012: 809]). Such vertical coordinated action enables the integration team to transfer comprehensive information on system-wide task demands toward component teams (Davison et al., 2012; Galbraith, 1994) and, as such, may strengthen IFD's positive consequences for horizontal coordination 
FIGURE 1

Conceptual Model

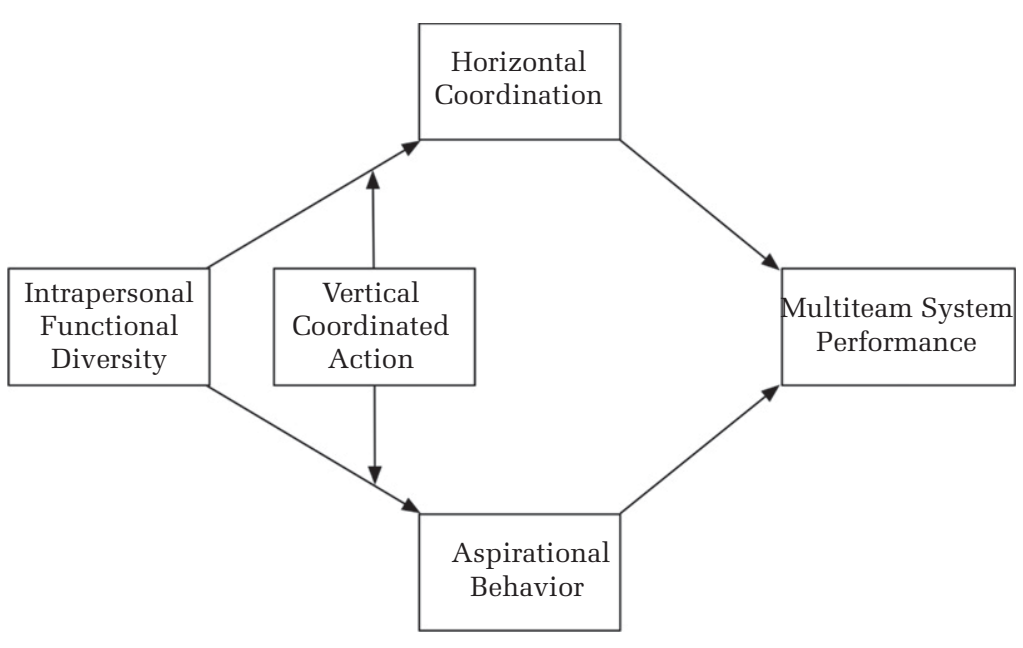

and neutralize IFD's negative implications for aspirational behavior (see Figure 1).

We examined these notions in a sample of 236 multiteam systems comprising 3,304 individuals engaged in a series of realistic computer simulations while attending a leadership development program with tangible career consequences. This setting enabled us to overcome the "onerous research obstacles" (Gulati, 1998: 306) that have limited past empirical research in this area (e.g., compiling a sufficiently large sample of comparable multiteam systems [DeChurch \& Zaccaro, 2010]).

Taken together, this research aims to advance our understanding of the antecedents associated with critical processes (horizontal coordination and aspirational behavior) and performance outcomes in multiteam systems. We illustrate how combining insights from micro-level $\mathrm{OB}$ and macro-level OT literatures enables important theoretical advances in multiteam system research (DeChurch \& Zaccaro, 2010; Zaccaro et al., 2012) and, more generally, in research on collaborative task accomplishment (Marrone, 2010; Smith et al., 1995). Moreover, this study is important for management practice because it points to proximal antecedent variables (IFD and vertical coordinated action) that organizations can manipulate through readily available interventions, thereby enabling managers to shape horizontal coordination, aspirational behavior, and overall performance as critical, yet difficult-to-influence, aspects of multiteam system functioning.

\section{THEORY AND HYPOTHESES}

\section{IFD as a Multiteam System Property}

Consistent with previous team-level research (e.g., Bunderson \& Sutcliffe, 2002), we conceptualize IFD as a configural unit property (Kozlowski \& Klein, 2000), representing the degree to which a multiteam system is composed of broad generalists with experiences that are dispersed across the system's multiple functional domains, as opposed to narrow specialists with experiences focused in a single domain. Unlike interpersonal functional diversity, which reflects differences across members with regard to the functional domains in which they have obtained most of their work experience, intrapersonal functional diversity considers differentiation within individuals. As such, IFD captures the full spectrum of members' work experiences (Burke \& Steensma, 1998; Joshi et al., 2009). IFD is highest when every multiteam system member has experience in all functional domains relevant to the system, and it is lowest when every member's task-related experience is focused in a single domain. A multiteam system's IFD can be increased, for example, through inter-functional rotations, team member exchanges (Leenders \& Wierenga, 2002), and cross-training within different functional domains (Marks et al., 2002).

\section{IFD and Multiteam System Performance}

Promoting horizontal coordination: IFD's potential benefits. Research originating from a micro-OB tradition has put forward theoretical and empirical 
arguments to support IFD's value for multiteam systems. Scholars have noted that broad functional backgrounds enable members to sense "the web of relationships" (Raskas \& Hambrick, 1992: 10) that connects their activities within the overall system and to better understand other system parts' functioning (Ford \& Schmidt, 2000; Joshi et al., 2009; Kusunoki \& Numagami, 1998). Hence, IFD may promote mutual knowledge regarding roles, tasks, and responsibilities within a multiteam system (Cannon-Bowers et al., 1998; Ellis \& Pearsall, 2011; Marks et al., 2002). This mutual knowledge reduces component teams' need to discuss and clarify task-related issues with each other, thereby enabling them to implicitly and seamlessly coordinate efforts when working on joint tasks (Entin \& Serfaty, 1999; Kotha, George, \& Srikanth, 2013). Without IFD, component teams need to repeatedly engage in cumbersome interactions because they do not sufficiently understand each other's specialized task competences, resources, and constraints (Cramton, 2001; Kotha et al., 2013; Srikanth \& Puranam, 2011). In other words, higher IFD may provide multiteam systems with crucial, "tacit" mechanisms of horizontal coordination, thereby potentially enabling component teams to realize such coordination in an efficient, bottom-up manner (Srikanth \& Puranam, 2011: 855; see also Puranam, Raveendran, \& Knudsen, 2012).

Horizontal coordination, in turn, may promote multiteam system performance by preventing redundancies and inconsistencies between different component teams' activities (Hoegl et al., 2004; Lanaj et al., 2013). In addition, component teams may receive crucial support from each other through horizontal coordination, which enables them to better execute key tasks for the system as a whole (Joshi et al., 2009; Marrone, 2010). As such, horizontal coordination is generally regarded as fundamental for efficiently and effectively realizing collective outcomes (DeChurch \& Mathieu, 2009; Mathieu et al., 2001). Research on rail-control multiteam systems, for example, has shown such coordination to allow component teams from various carriers, network operators, and contractors to combine their expertise and, thus, to effectively solve joint operational problems (Goodwin et al., 2012).

However, IFD's value for horizontal coordination and multiteam system performance is not as clearcut as the above arguments might suggest. Despite its well-documented importance within standalone teams (e.g., Bunderson \& Sutcliffe, 2002; Park et al., 2009; Rulke \& Galaskiewicz, 2000), IFD's consequences for more complex multiteam systems have not been studied. Moreover, empirical research in larger organizational units has painted an inconsistent picture. Parry and Song (1993), for example, found that multifunctional members strengthened integration between organizational units, whereas Leenders and Wierenga (2002) found that moving personnel across different functional departments did not aid such integration (see also Maltz \& Kohli, 2000). Hence, it is unclear whether the positive relation between IFD and horizontal coordination (and, ultimately, performance) observed in standalone teams will translate toward multiteam systems.

Diminishing aspirational behavior: IFD's potential downsides. Besides IFD's potential benefits for horizontal coordination, it is important to note that IFD might, at the same time, come with the undesirable side effect of constraining a multiteam system's aspirational behavior. As noted above, such behavior reflects a system's engagement in complex, specialist activities that are instrumental to the realization of its key strategic goals (Lanaj et al., 2013). A primary reason for these adverse effects of IFD is that frequent functional rotations leave members with little time to develop specialist insights within any particular work domain (Buyl, Boone, Hendriks, \& Matthyssens, 2011). Consequently, members may lack the knowledge and experience required for effectively performing complex, aspirational tasks within specific domains. Members may, then, be tempted to forgo complex domain-specific activities in the multiteam system (Postrel, 2002: 360) and adopt "tactical modes of professional behavior" by concentrating on simpler, less ambitious courses of action (Jans \& Frazer-Jans, 2004: 258).

Neglecting these adverse side effects may have far-reaching ramifications, because aspirational behavior is fundamental for multiteam system performance (Lanaj et al., 2013). To return to the example of a rail-control multiteam system, it is a strategic goal of such systems to recover as quickly and robustly as possible from network disturbances. Accomplishing this goal requires that a multiteam system goes beyond the mere treatment of surface-level symptoms to identify and correct the root causes underlying a disturbance (Jans \& Frazer-Jans, 2004; Postrel, 2002). Limited aspirational behavior may suffice to ameliorate a disturbance's direct consequences, but it is unlikely to effectively address long-term ramifications for the rail network as a whole. In fact, low aspirational behavior may even hurt system performance in the long run, because this approach 
typically "doubles the [subsequent] repair effort and associated costs" (Goodwin et al., 2012: 60). In line with this argument, previous team-level research has found that members can realize more advanced contributions for their team when deliberately working toward more difficult and aspirational goals (Knight, Durham, \& Locke, 2001). Initial empirical work at the multiteam system level has mirrored these findings, suggesting a positive relationship between aspirational behavior and multiteam system performance (Lanaj et al., 2013).

\section{Triggering Alternative Pathways: The Role of Vertical Coordinated Action}

Interestingly, a different research paradigmoriginating from an OT tradition-may clarify IFD's countervailing effects in multiteam systems. The $\mathrm{OB}$ perspective discussed above examines how compositional characteristics (such as IFD) shape horizontal coordination and aspirational behavior in an emergent, bottom-up manner. In contrast, the OT perspective focuses on formal, top-down mechanisms (e.g., Brown, 1999; Galbraith, 1994; Lawrence \& Lorsch, 1967). This latter perspective has identified integration teams, in particular, as crucial for multiteam systems (Browning, 1998; Davison et al., 2012). Integration teams are a formal part of a multiteam system's structure; they are responsible for ensuring effective coordination between specialized component teams and realization of the overall system's strategic goals (Davison et al., 2012; DeChurch \& Marks, 2006). For these purposes, integration teams typically hold a central position in the flow of work, with members dedicated to spanning boundaries between component teams (DeChurch \& Marks, 2006; Goodwin et al., 2012). This unique role allows integration teams to develop "big-picture information" on real-time coordination and strategic demands in the wider system (Davison et al., 2012: 812).

It is important to note, however, that integration teams typically cannot singlehandedly realize a multiteam system's operational tasks because they lack the time, manpower, and specialized expertise to substitute for component teams' efforts (Brown, 1999; Galbraith, 1994). Rather, integration teams' core responsibility is to utilize their unique, broad perspective to guide and support component teams' operational task accomplishment (Galbraith, 1994). To effectively meet this responsibility, it is crucial that integration teams frequently connect with different component teams to align task-related matters-an internal multiteam system process we label vertical coordinated action (Davison et al., 2012). This process enables integration teams to transmit and clarify their big-picture information on coordination demands and strategic requirements toward component teams. Component teams can then act upon such information by engaging in horizontal coordination and aspirational behavior. Clearly, however, these potential benefits associated with vertical coordinated action hinge on whether component teams can put the integration team's insights to effective use-and we propose that IFD plays a key role in this regard.

As such, we argue that OB and OT perspectives complement each other to enable a better and more comprehensive picture of multiteam system functioning. OB research provides a useful starting point for understanding how component teams' capacities-as derived from IFD—may shape multiteam system processes, but it does not speak to the role of the organizational structure in which such bottom-up processes take place (House, Rousseau, \& Thomas-Hunt, 1995). Macro-level OT research, on the other hand, has considered the role of top-down organizational context factors by focusing on formal integration teams, but has generally ignored crucial bottom-up factors that can implicitly organize joint efforts (Browning, 1998; Davison et al., 2012; House et al., 1995; for a recent exception, see Srikanth \& Puranam, 2011). Consequently, we follow recent theoretical developments (e.g., Kotha et al., 2013; Srikanth \& Puranam, 2011; see also Gioia \& Pitre, 1990) by adopting a multi-paradigm approach that integrates insights from the OB and OT literatures to study multiteam systems. As depicted in Figure 1, we suggest that IFD and vertical coordinated action are intertwined in a complex manner, with vertical coordinated action determining whether IFD's advantages (increased horizontal coordination) or disadvantages (decreased aspirational behavior) will prevail.

The role of vertical coordinated action in the relationship between IFD and horizontal coordination. If IFD is to effectively stimulate horizontal coordination within a multiteam system, it is crucial that members have a thorough overview of systemwide activities and coordination demands (Espinosa, Slaughter, Kraut, \& Herbsleb, 2007; Klein \& Pierce, 2001). Equipped with this overview, members can draw from their IFD and implicitly coordinate their own component team's activities with other teams (DeChurch \& Marks, 2006). Unfortunately, however, multiteam systems' large-scale and dynamic nature 
often prevents component team members from being informed about all activities and coordination requirements in the system as a whole (Browning, 1998; Davison et al., 2012). Integration teams are likely to play a critical role in addressing this issue, because their central location in the flow of work uniquely positions them to gain real-time, comprehensive information on the overall system (Brown, 1999; DeChurch \& Marks, 2006; Galbraith, 1994) and to transfer such information to component teams through vertical coordinated action.

Thus, we anticipate that vertical coordinated action will strengthen the positive relationship between IFD and horizontal coordination. Multiteam systems with high IFD have the mutual knowledge necessary to enact implicit horizontal coordination (Cramton, 2001), and they receive crucial information from the integration team in order to employ this knowledge when vertical coordinated action is high (DeChurch \& Marks, 2006). Multiteam systems that are low in IFD, on the other hand, may be unable to enact effective horizontal coordination even when the integration team exhibits strong vertical coordinated action. In such circumstances, the system is likely to experience difficulties in sensing relationships between different teams' activities and implicitly structuring and aligning component teams' contributions (Ford \& Schmidt, 2000; Kusunoki \& Numagami, 1998; Srikanth \& Puranam, 2011). Hence, despite the integration team's efforts, horizontal coordination is likely to remain limited by misunderstandings and cumbersome interaction processes between component teams.

In contrast, IFD is less likely to positively relate with horizontal coordination in multiteam systems with lower vertical coordinated action. In this situation, the integration team fails to support component teams' horizontal coordination (Mathieu et al., 2001). With low IFD it is clear, then, that horizontal coordination is unlikely to occur. After all, component teams lack the mutual knowledge required to implicitly account for each other's demands (Ford \& Schmidt, 2000; Joshi et al., 2009), and the integration team provides little information to facilitate such efforts (Davison et al., 2012; DeChurch \& Marks, 2006). Thus, the difficulties of aligning actions across component teams may overburden members' limited capacities (Faraj \& Yan, 2009; Marrone, 2010). Even multiteam systems with functionally broad members (high IFD), however, are unlikely to effectively use their mutual knowledge for horizontal coordination when vertical coordinated action is lacking. Under these circumstances, component teams have to uncover coordination requirements through explicit and cumbersome interactions before they can align their efforts (Browning, 1998; Davison et al., 2012). Hence, without adequate integration team support, much of IFD's potential is likely to be spent on preparatory actions rather than horizontal coordination itself.

Taken together, we predict that vertical coordinated action will allow multiteam systems to more effectively utilize their IFD for horizontal coordination, thereby strengthening IFD's performance benefits. With little vertical coordinated action, in contrast, these performance benefits should remain limited, as the positive relationship between IFD and horizontal coordination is less likely to materialize.

Hypothesis 1. Vertical coordinated action moderates the indirect relationship between IFD and multiteam system performance, as mediated by horizontal coordination. This positive indirect relationship is accentuated when vertical coordinated action is higher and attenuated when vertical coordinated action is lower.

The role of vertical coordinated action in the relationship between IFD and aspirational behavior. Besides the coordination advantages described above, integration teams' central role within multiteam systems should enable them to obtain an overarching perspective on progress against the system's strategic goals (DeChurch \& Marks, 2006; Galbraith, 1994; Klein \& Pierce, 2001) and to transfer strategically important information out to component teams through vertical coordinated action. In multiteam systems with high IFD, vertical coordinated action may therefore compensate for component teams' pragmatic orientation toward immediate and obvious tasks and away from high-impact, yet difficult, activities (Jans \& FrazerJans, 2004). Under such conditions, the integration team can emphasize core strategic directions for the system as a whole and direct component teams' efforts toward challenging, specialized activities that advance such goals (Brown, 1999; Mathieu et al., 2001). Even multiteam systems with high IFD are likely, then, to retain a focus on aspirational activities during task execution, thereby diminishing the negative relationship between IFD and aspirational behavior.

In contrast, IFD's negative consequences for aspirational behavior should surface particularly strongly when vertical coordinated action is less pronounced. In such situations, the integration 
team fails to guide the system toward high-impact and strategically important goals (Browning, 1998; Klein \& Pierce, 2001). Multiteam systems comprising functionally narrow specialists (low IFD) may be able to exhibit aspirational behavior to some degree even in this context, because members have thorough domain-specific knowledge that allows them to identify and execute complex tasks related to their specialized work domain (Postrel, 2002). In multiteam systems with high IFD, however, generalists' broad and relatively superficial perspective on specialized tasks may focus them on immediate, less challenging, and low-impact activities, and a lack of vertical coordinated action is likely to exacerbate this orientation. The integration team does little to redirect functionally broad members' focus toward strategic, high-impact goals in this context, thereby sustaining the overall system's narrow functional outlook.

Taken together, we predict that strong vertical coordinated action can compensate for IFD's negative performance effects by diminishing the inverse association between IFD and aspirational behavior. With low vertical coordinated action, however, increasing IFD is likely to go along with substantial decrements in aspirational behavior and, thus, to deteriorate a multiteam system's performance outcomes.

Hypothesis 2. Vertical coordinated action moderates the indirect relationship between IFD and multiteam system performance, as mediated by aspirational behavior. This negative indirect relationship is accentuated when vertical coordinated action is lower and attenuated when vertical coordinated action is higher.

\section{METHODS}

\section{Research Design and Sample}

We tested our hypotheses using a sample comprised of 3,304 United States Air Force officers attending a five-week leadership development course. Participants represented a broad range of job categories and had between five and nine years of professional work experience. As part of the course, participants were assigned to 236 fourteen-person multiteam systems that worked together on a series of realistic computer-based decision-making simulations (i.e., the Leadership Development Simulation [LDS]). These simulations formed the basis for the present study. During the simulations, participants dealt with tasks that were highly similar to their regular jobs. Their performance was part of their overall course evaluations and influenced future advancement and promotion opportunities. As such, this study combined elements of both laboratory (e.g., high control and standardization across all multiteam systems) and field (e.g., a realistic sample with tangible consequences tied to participants' task performance) research.

Each multiteam system participated in three independent LDS sessions (with equivalent procedures and identical membership) during the course of the leadership development program. Data for the present investigation is mainly based on the third and final simulation session. Air Force trainers assigned participants to a specific multiteam system to ensure competitive fairness and equivalent composition (e.g., in terms of age, gender, occupational category, etc.). In addition, task difficulty and complexity was held constant by using the exact same configuration of the simulation across all 236 multiteam systems within each of the LDS sections. All participants received comprehensive training prior to their first LDS session, which included reading material, an illustrated presentation, and three practice rounds. Moreover, the multiteam systems received a limited intelligence briefing, and could use 10 minutes before the start of a simulation session for initial planning and goal setting. The multiteam systems then participated in computer-based simulations lasting roughly 120 minutes per session.

This study was part of a larger research program designed to comprehensively advance scientific knowledge on multiteam systems. We were unable to control or manipulate IFD in this context (e.g., through random assignment to different IFD conditions), because (a) simulation results had tangible implications for participants' career advancement and (b) we expected potential disadvantages associated with IFD (e.g., reduced aspirational behavior). Hence, we used a priori screening criteria to select comparable multiteam systems from the overall research program that had similar opportunities to develop and apply IFD (for similar approaches, see Holloway \& Parmigiani, 2014; Reuer \& Devarakonda, 2015; Schulze, Lubatkin, \& Dino, 2003). Specifically, we included all multiteam systems that had remained (a) intact across all three LDS sessions (i.e., no membership additions or losses), and (b) stable after developing different levels of IFD across the first and second LDS sessions (i.e., no changes in members' functional roles between the second and third sessions). These criteria built on the notion that (a) IFD and performance in the third and final session 
are only comparable between multiteam systems with constant membership, and (b) IFD's implications could fully surface in the final session only in multiteam systems that had finished developing IFD after the second session. With regard to the latter point, we expected multiteam systems to experience performance decrements during the process of developing IFD, as its members rotated toward new functional domains and needed to adjust to an unfamiliar task. These performance decrements should be temporary, however, as they reflect short-term adjustment problems rather than general IFD characteristics (i.e., members' broad, yet superficial, experiences). By focusing on multiteam systems that had finished developing IFD after the second LDS session, we could prevent such temporal problems from confounding IFD's effects during the third session.

As is common in large-scale research efforts (e.g., Huxham \& Vangen, 2000), the overall research program was designed to produce several studies on different aspects of multiteam system functioning. Consequently, some of the multiteam systems in the present sample (39 to $47 \%$ ) had also been used in prior studies (Davison et al., 2012; Firth, Hollenbeck, Miles, Ilgen, \& Barnes, 2014; Lanaj et al., 2013). ${ }^{1}$ Importantly, however, the data from the third LDS session used here have not been previously examined, and no other study in this program has examined IFD. The present study is thus unique both empirically and conceptually. In addition, we note that our results are robust when controlling for key variables included in previous studies.

\section{Multiteam System Simulation}

Task. The LDS was a computer-based simulation during which all 14 participants within a multiteam system were colocated and free to communicate with each other. ${ }^{2}$ The simulation created a complex and dynamic task environment that required multiteam system members to work interdependently and under time pressure to deploy a large number of assets (i.e., remotely piloted aircraft [RPAs] and intelligence assets) to achieve the common goal of maximizing the system's overall point score. Points could be gained by successfully engaging a variety of targets hidden in a 256-cell task environment, and points were lost when RPAs or their home base were attacked.

\footnotetext{
${ }^{1}$ A detailed description of the overlap between studies' samples is available from the second author upon request.

${ }^{2}$ See Davison et al. (2012) for a detailed description of LDS.
}

Targets' point value varied by size and class, with large "opportunities" carrying the highest and small "threats" carrying the lowest value. Threats (but not opportunities) had the ability to attack RPAs and the home base. To increase environmental uncertainty and problem-solving workload, target types were initially disguised for half of the targets in the third session. Participants therefore had to collaboratively engage in a process of exploration, experiential learning, and reasoning to discover these targets' attributes. Initial target placements, as well as target types and movements, were identical for all multiteam systems.

Multiteam system composition and roles. Multiteam systems contained three types of teams: two component teams (point and support) and an integration team. The point team's primary role was to engage targets, whereas the support team's role was to provide intelligence on targets' location and identity. Each of the two component teams comprised four staff members with specific operational responsibilities, as well as two boundary spanners (denoted director and assistant director). The point team's individual staff members each controlled one category of identical RPAs with unique capabilities (i.e., "Strike" for engaging opportunities, "Escort" for neutralizing threats, "Info" for providing information on targets' identity, and "Refuel" for refueling other RPAs for long-distance missions). Moreover, each of the four support team staff members controlled one unique category of intelligence assets with distinct "sweet spots" (i.e., a limited zone in the simulation environment in which the respective asset provided reliable information on target identity). Intelligence assets' sweet spots were unknown at the start of the simulation, and participants thus had to uncover these zones through collective exploration and shared learning.

Multiteam systems also included an integration team, which comprised the four boundary spanners from the component teams and two additional members (denoted mission commander and vice commander). This integration team was tasked with a boundary-spanning role to facilitate component teams' cooperation and task accomplishment. Scholars have noted that enactment of this role can vary along a continuum from "liaison" to "integrative leadership." Liaison roles employ nonhierarchical means (e.g., information collection and dissemination), whereas integrative leadership roles rely on formal decision authority (Galbraith, 1994; Sherman \& Keller, 2011; Sinha \& Van de Ven, 2005). In the present case, one half of the integration team 
(the vice commander and assistant directors) enacted liaison roles without formal authority, whereas the other half (the mission commander and the two directors) had integrative leadership roles. All of these members were required to work closely together as a team to effectively meet their joint responsibilities. Liaison members, in particular, had a supportive function within the integration team; their core task was to assist decision making by collecting, integrating, and disseminating information on component teams' actions. Integrative leaders critically required such information to make purposeful leadership decisions, whereas liaisons needed integrative leaders' inputs and feedback to guide their information collection activities and enable them to effectively prepare and communicate such information.

A distinctive feature of the multiteam systems studied here is that a system's individual teams had to collaborate to jointly ensure the system's overall success. Integration teams, for example, lacked the capacity for deploying all assets in a timely and effective manner; as such, they required component teams' contributions for operational task accomplishment. Component teams, in turn, were ill positioned to uncover broad, overarching information about coordination demands and strategic task requirements in the system as a whole; consequently, they depended on the integration team for such insights. Finally, there was considerable interdependency between component teams. Point teams had to rely on support team intelligence to effectively deploy their RPAs, and support teams required point team input to identify intelligence assets' sweet spots and efficaciously enact intelligence-gathering activities.

Simulation setup. Participants were presented with a blank grid representing the task environment at the start of a simulation. Hidden throughout the grid were threat and opportunity targets that varied along the aforementioned attributes. As previously discussed, threats that attacked RPAs and the home base resulted in point losses, and points could be earned when neutralizing threats. Opportunities similarly earned points for the multiteam system when engaged successfully, but they posed no threat of attack. To illustrate the simulation's complexity, we note that different RPAs were needed to engage different types of targets, and that successful neutralization of some targets required simultaneous attacks through multiple RPAs. In addition, some targets remained in the same location during the entire simulation, whereas others moved around the simulation grid. Any location in the task environment could be void of targets or could contain one or two targets.

A complete LDS session consisted of 10 decisionmaking rounds. In each round, component team members first recommended specific asset deployments to their director. Directors then reviewed these recommendations, made alterations if deemed appropriate, and passed the revised set of recommendations on to the mission commander for his or her review, alteration, and final approval. A multiteam system's RPAs and intelligence assets were then deployed and interacted with the simulation environment according to this final set of decisions. Collectively, the deployment process required 144 decisions in each round within a limited amount of time. Component team members received feedback on their assets' interactions with the task environment and had a limited amount of time afterward to analyze this feedback and plan deployments for subsequent rounds. Successfully engaged targets were removed from the task environment, whereas destroyed RPAs were replaced at the start of the next round. All in all, effective performance required a multiteam system to collectively manage a large number of RPAs and intelligence assets under pressure of time in order to successfully pursue different types of opportunities and neutralize diverse threats.

Information management. Each multiteam system used an information exchange system called the Common Operating Picture (COP)—a digital map of the task environment that provided a means of sharing information regarding encountered targets' type and location. Component teams could employ the COP to record information on self-identified targets for future reference and to organize collective task achievement. The support team, for example, could employ the COP to provide the point team with intelligence about potential targets, whereas the point team could utilize the COP to give feedback on the accuracy of such intelligence. Based on this information, component teams could then develop subsequent deployments. Importantly, use of the COP was not obligatory; the point team was free to rely exclusively on knowledge gathered by its own assets, and the support team could rely solely on the formal feedback provided in the LDS. In addition, given its retrospective nature, the COP did not convey any information concerning component teams' planned asset deployments.

The integration team's liaison members (i.e., the vice-commander and assistant directors) facilitated 
the component teams' use of the COP by updating it when new targets had been uncovered or known targets had been destroyed. Liaison members did not have direct access to the information needed to update the COP, however; they were dependent on input from the component teams. Moreover, the integration teams' liaison members did not have the authority to prescribe the information component teams would gather for display on the COP or to enforce the use of such information for subsequent deployments.

\section{Measures}

Consistent with previous research using the LDS, all constructs in this study were conceptualized as configural unit properties (Kozlowski \& Klein, 2000) at the multiteam system level of analysis.

Intrapersonal functional diversity. We operationalized IFD as the proportion of members in a multiteam system that had acquired experiences across different functional domains during the first two LDS sessions (see Park et al., 2009, for a similar approach). Specifically, during the first LDS session individual participants worked in one of the four distinct functions described above and, consequently, gained hands-on experience in the respective domain (i.e., operations [point team], intelligence [support team], and liaison or integrative leadership [integration team]). For the second LDS session, some participants remained within their original function, whereas others switched to a different domain. Notably, due to the screening criteria described above, participants in our sample did not change domains between the second and third sessions. Further, members remained within the same multiteam system across LDS sessions, such that functional rotations only took place within (not between) the respective systems. We note that the decision to switch members' functional domains was within a multiteam system's own discretion. Consistent with prior team-level research (e.g., Bunderson \& Sutcliffe, 2002; Buyl et al., 2011; Cannella et al., 2008), we capitalized on these naturally occurring role transfers to capture IFD.

Whether participants rotated between different domains had important implications for their functional knowledge. The LDS was designed to enable participants to grasp a domain's basic tasks, demands, and constraints within a single session. At the same time, the simulation's dynamism and difficulty made it virtually impossible to develop sophisticated, specialized knowledge in a functional domain after a single episode. Different LDS sessions had different target distributions, therefore exposing participants to unique challenges that forced them to rethink and refine their existing knowledge. Hence, participants that remained in the same function for two consecutive sessions could reflect on their actions from the first session, get feedback, and try out different solutions in the second session. These participants were able, therefore, to develop deeper, more specialized knowledge compared to participants who switched to a different function after the first session.

These advantages notwithstanding, remaining in a single domain also limited participants' breadth of functional knowledge. Different LDS domains posed distinct challenges and, thus, it was not possible for members to simply apply what they had learned in one function toward other domains. Experience in the support team (such as finding assets' sweet spots), for example, provided little help with the point team's specific challenges (such as destroying hostile targets while keeping the home base protected). Hence, only participants that switched between functional domains during consecutive LDS sessions had the opportunity to develop broad, generalist functional knowledge, although these participants could not deepen their knowledge within any single domain.

Overall, $63 \%$ of our study participants remained in their initial functional domain after the first LDS session, and $37 \%$ switched to a different domain. Importantly, the number of participants switching functional roles within a multiteam system differed considerably across the systems in our sample, ranging from 0 to 14 (all) members $(M=5.18$; $S D=$ 4.59). After the second simulation session, therefore, the degree to which multiteam systems comprised specialist members with narrow experiences (i.e., experiences in only one functional domain) versus generalist members with broader experiences (i.e., experiences in two functional domains) varied widely. In addition, the present measure of IFD was normally distributed (skewness $=.34$, n.s.) and unrelated to past multiteam system performance $(r=$ .12 , n.s.), past horizontal coordination ( $r=-.08$, n.s.), past aspirational behavior ( $r=-.07$, n.s.), and past vertical coordinated action ( $r=-.01$, n.s.). Hence, we can rule out some important confounds with regard to our key independent variable.

Horizontal coordination. Consistent with Lanaj et al. (2013), we measured horizontal coordination as the number of point team missions based upon intelligence discovered by the support team in the 
preceding rounds and captured on the COP. ${ }^{3} \mathrm{~A}$ large number of such missions indicates effective horizontal coordination, such that (a) the support team has accurately anticipated the point teams' information requirements, has aligned its asset deployments accordingly, and has shared the resulting intelligence on the COP, and (b) the point team has understood the respective information's relevance and has acted upon it in a timely manner. Importantly, horizontal coordination does not simply denote component teams' general use of the COP, since the support team could also share intelligence on the COP that was not useful for the point team (and was therefore not used for point team missions), and the point team could also display (and later engage) selfidentified targets on the COP.

Besides horizontal coordination between overall component teams (as captured in the present measure [Lanaj et al., 2013]), scholars have also discussed dyadic coordination between individual component team members (Davison et al., 2012). We focused on horizontal coordination across the multiteam system as a whole because such coordination represents synergistic efforts that can facilitate overall system performance (e.g., DeChurch \& Marks, 2006; Lanaj et al., 2013; Marrone, 2010). The consequences of individual members' dyadic coordination are less clear; these activities may align with or counteract the actions of other multiteam system parts and, therefore, may have ambiguous performance effects (Davison et al., 2012; Klein \& Pierce, 2001).

Aspirational behavior. Although aspirational behavior may be diverse, multifaceted, and difficult to measure in the field, the present laboratory context provided a controlled setting that enabled clear-cut, behavioral measurement of this construct. In particular, targets in the LDS varied considerably in value (i.e., points to be gained by engaging a target), and it was imperative that multiteam systems pursued high-value targets to achieve high overall performance. At the same time, these high-value targets were particularly difficult to engage because they were (a) located in the remote half of the task environment and (b) well protected and mobile. Consequently, successful engagement of these targets required simultaneous deployment of multiple specialized RPAs (e.g., strike, refuel, and escort), and

\footnotetext{
${ }^{3}$ Lanaj et al. (2013) reverse coded this measure to capture component teams' failure to engage in horizontal coordination. In the present manuscript, horizontal coordination is not reverse coded; higher scores thus denote greater horizontal coordination.
}

members had to deliberately forgo less challenging targets to pursue these opportunities. Multiteam system members were informed during presimulation briefings on both the importance and difficulty of pursuing high-value targets.

We therefore captured aspirational behavior as the number of operations missions sent to the remote half of the task environment in pursuit of high-value targets. ${ }^{4}$ This measure represents a prime form of aspirational behavior in the present context, reflecting a highly complex, specialized type of activity that pushes a multiteam system's performance boundaries (Lanaj et al., 2013). A system exhibited high aspirational behavior, in particular, when its members frequently pursued remote, valuable targets with complex "packages" of multiple RPAs. In contrast, when a system was low in aspirational behavior, most of its missions involved single RPAs directed at low-value targets that did not require refueling (because they were close to the base), escort (because they were unprotected), or tracking (because they were stationary).

Vertical coordinated action. Integration team members with leadership roles (i.e., the mission commander and directors) had formal authority to modify and accept component teams' asset deployment decisions. Following Davison et al. (2012), we operationalized vertical coordinated action as the number of lower-level decisions modified in this process. We reverse-coded this measure, such that higher values (less modification) represent greater vertical coordinated action. ${ }^{5}$

\footnotetext{
${ }^{4}$ Aspirational behavior is conceptually different from risk taking. Although high-impact specialized tasks may pose risks in some circumstances, this is not a defining feature of such aspirational behavior (i.e., there may be high-impact tasks that involve little risk [Lanaj et al., 2013]). Correspondingly, in the present sample, aspirational behavior and risk taking (i.e., the number of unescorted deployments to unknown areas where assets' safety was unclear) were moderately positively correlated $(r=.38, p<.01)$.

${ }^{5}$ Multiteam systems controlled 16 RPAs and 32 intelligence assets; consequently, the integration team could modify twice as many support team decisions as point team decisions. To prevent distortion, we therefore standardized modifications within component teams before calculating an average multiteam system score. We note that a validation study by Davison et al. (2012) found this vertical coordinated action measure to positively relate with participants' perceptions of vertical coordination ( $r=.43, p<.05$; corrected for attenuation).
} 
With high vertical coordinated action, asset deployment decisions were aligned and coherent across hierarchical layers in the multiteam system and, thus, there was no reason to modify component team decisions (Davison et al., 2012). Importantly, given the large number of deployment alternatives in the simulation, it is implausible that integration and component teams would coincidentally agree on a coherent set of decisions. In addition, considering that participants were observed for promotion, it is unlikely that integration team leaders would passively and uncritically accept component team decisions. ${ }^{6}$ Hence, few higher-level modifications reflect high vertical coordinated action. In case of low vertical coordinated action, on the other hand, asset deployment decisions were misaligned and incompatible across hierarchical layers, causing the integration team to veto or change a large number of component team decisions. Hence, many higher-level modifications reflect a relative lack of vertical coordinated action.

We note that the present measure of vertical coordinated action (drawn from Davison et al., 2012) differs from the vertical coordination dimension within Lanaj et al.'s (2013) broader coordination failures construct. Whereas Lanaj et al. (2013) measured only instances in which a lack of vertical coordination affected multiteam system performance, our measure captures vertical coordinated action without regard for its performance consequences. As such, the current measure is appropriate for the present purposes.

Multiteam system performance. We operationalized a multiteam system's performance as the sum of points gained from successfully engaging targets minus points lost through hostile attacks during the third LDS session. This measure represents a system's collective, overall performance (Davison et al., 2012; Lanaj et al., 2013).

Control variables. To rule out possible biases from differences in training effectiveness and task mastery, we controlled for multiteam system performance during the LDS session immediately preceding the one reported here (i.e., session 2) when examining performance consequences of horizontal coordination and aspirational behavior.

\footnotetext{
${ }^{6}$ During observations of the multiteam systems and debriefing sessions, we did not encounter any behaviors that would suggest a lack of engagement or commitment.
}

\section{Data Analysis}

We used hierarchical linear regressions at the multiteam system level to test the interactive relationships of IFD and vertical coordinated action with the mediators (horizontal coordination and aspirational behavior), as well as the relationships between these mediators and multiteam system performance. Further, to examine the full moderatedmediation hypotheses, we used a bootstrap approach to estimate indirect relationships between IFD and multiteam system performance (mediated by horizontal coordination and aspirational behavior) at higher and lower levels of vertical coordinated action ( \pm 1 SD). We interpreted bias-corrected 95\% confidence intervals to assess the conditional indirect relationships' statistical significance (Edwards \& Lambert, 2007). We standardized all predictor variables prior to the analyses.

\section{RESULTS}

\section{Descriptive Statistics}

Table 1 depicts means, standard deviations, and bivariate correlations for all variables. As expected, the direct associations of IFD with horizontal coordination ( $r=.09$, n.s.) and aspirational behavior $(r=-.03$, n.s.) were non-significant, underlining the potential relevance of considering moderating factors for these relationships. In addition, previous performance was significantly related with multiteam system performance in the focal, third LDS session $(r=.31, p<.01)$ and, therefore, was an important covariate (Becker, 2005).

\section{Hypotheses Testing}

Hypothesis 1 predicted that the indirect, positive association between IFD and multiteam system performance, through horizontal coordination, would be stronger when vertical coordinated action was higher rather than lower. To test this hypothesis, we first regressed horizontal coordination on IFD, vertical coordinated action, and the multiplicative term of IFD $\times$ vertical coordinated action. As shown in Table 2, we found a significant interactive relationship $(B=1.84, S E=.86, p<.05)$. The association between IFD and horizontal coordination was positive when vertical coordinated action was higher (simple slope at $+1 \mathrm{SD}=2.80, S E=1.15, p<.05$ ), whereas this relation did not reach significance when vertical coordinated action was lower (simple slope at $-1 \mathrm{SD}=-0.87, S E=1.26$, n.s.). We then 
TABLE 1

Means, Standard Deviations, and Correlations

\begin{tabular}{|c|c|c|c|c|c|c|c|}
\hline Variables & $M$ & $S D$ & \multicolumn{5}{|c|}{$\boldsymbol{r}$} \\
\hline 2. IFD & 0.37 & 0.33 & 0.09 & & & & \\
\hline 3. Vertical coordinated action & 0.17 & 2.36 & -0.07 & 0.05 & & & \\
\hline 4. Horizontal coordination & 51.50 & 13.20 & 0.07 & 0.09 & $0.20^{* *}$ & & \\
\hline
\end{tabular}

examined the performance implications of horizontal coordination. Even when controlling for past performance, IFD, and aspirational behavior, we found a significant positive relationship between horizontal coordination and multiteam system performance $(B=$ 7.50, $S E=2.87, p<.01$; see Table 3).

In the final step of examining Hypothesis 1, we inspected the conditional indirect relationship between IFD and multiteam system performance, as mediated by horizontal coordination, at different values of vertical coordinated action. This indirect relationship was positive at higher levels of vertical coordinated action (indirect relationship at $+1 \mathrm{SD}=$ 20.99; $95 \%$ bootstrap CI $=3.90$ to 55.22 ). The indirect relationship was non-significant, however, when vertical coordinated action was lower (indirect relationship at $-1 \mathrm{SD}=-6.55$; $95 \%$ bootstrap $\mathrm{CI}=$ -34.49 to 9.91). Thus, Hypothesis 1 was supported.

Hypothesis 2 predicted that the indirect, negative relationship between IFD and multiteam system performance, through reduced aspirational behavior, would be more pronounced when vertical coordinated action was lower rather than higher. We found a significant interactive relationship between IFD, vertical coordinated action, and aspirational behavior $(B=$ 2.57, $S E=1.00, p<.05$; see Table 2). The association between IFD and aspirational behavior was negative when vertical coordinated action was lower (simple slope at $-1 \mathrm{SD}=-3.32, S E=1.46, p<.05$ ) but nonsignificant when vertical coordinated action was higher (simple slope at $+1 \mathrm{SD}=1.81, S E=1.33$, n.s.). As shown in Table 3, aspirational behavior was, in turn, positively related to multiteam system performance, even after controlling for past performance, IFD, and horizontal coordination $(B=5.90, S E=2.86, p<.05)$.

Tests of the overall conditional indirect association showed a negative indirect relationship between IFD and multiteam system performance, through aspirational behavior, under conditions of lower vertical coordinated action (indirect relationship at $-1 \mathrm{SD}=$ -19.59 ; $95 \%$ bootstrap CI $=-59.20$ to -1.25 ). This indirect relationship did not reach significance, however, when vertical coordinated action was higher (indirect relationship at $+1 \mathrm{SD}=10.68 ; 95 \%$ bootstrap CI $=-3.24$ to 37.98). Thus, Hypothesis 2 was supported.

Figure 2 illustrates the results for the conditional indirect relationships proposed in Hypotheses 1 and 2. ${ }^{7}$ As shown in Figure 2a, higher vertical coordinated action accentuated IFD's positive performance implications (through horizontal coordination) and attenuated its negative consequences (through aspirational behavior). In contrast, Figure $2 \mathrm{~b}$ shows that lower vertical coordinated action accentuated IFD's negative performance implications (through aspirational behavior) while attenuating its positive consequences (through horizontal coordination).

We employed binomial effect size displays to assess our results' practical significance (Rosenthal \& Rubin, 1982). Specifically, we examined the implications of the "best-case scenario" advanced in this research (i.e., high IFD combined with high vertical coordinated action) for multiteam systems' performance. In our sample of 236 multiteam systems,

\footnotetext{
${ }^{7}$ The interactive relationship between IFD, vertical coordinated action, and horizontal coordination remained almost identical when controlling for prior horizontal coordination $(B=1.58, S E=.82, p=.05)$. Similarly, the interactive relationship between IFD, vertical coordinated action, and aspirational behavior remained almost identical when controlling for prior aspirational behavior $(B=$ 1.96, $S E=.95, p<.05)$. Finally, all findings for aspirational behavior remained robust when controlling for risk taking.
} 
TABLE 2

IFD, Horizontal Coordination, and Aspirational Behavior

\begin{tabular}{|c|c|c|c|c|}
\hline & \multicolumn{2}{|c|}{ Horizontal coordination } & \multicolumn{2}{|c|}{ Aspirational behavior } \\
\hline Vertical coordinated action (VC) & $2.54(.85)^{* *}$ & $2.65(.84)^{* *}$ & $1.03(.98)$ & $1.19(.97)$ \\
\hline $\mathrm{IFD} \times \mathrm{VC}$ & & $1.84(.86)^{*}$ & & $2.57(1.00)^{*}$ \\
\hline R-square (adjusted) & $0.038^{* *}$ & $0.052 * *$ & 0.000 & $0.021^{*}$ \\
\hline
\end{tabular}

Note: $n=236$ multiteam systems. Unstandardized regression coefficients are shown; standard errors are noted within parentheses.

$* p<.05$

$* * p<.01$

$6.4 \%$ (i.e., 15 systems) had both IFD and vertical coordinated action scores at one standard deviation or more above the mean. These multiteam systems were clearly overrepresented among the topperforming systems, with $16 \%$ of the top- 25 performers exhibiting a best-case scenario. In fact, multiteam systems with high IFD and high vertical coordinated action were 2.5 times more likely to be in the top 25 compared to systems with lower IFD or vertical coordinated action. Moreover, multiteam systems exhibiting a "best-case scenario" were underrepresented among the worst-performing systems in our sample, representing only $4 \%$ of the bottom-25 performers. Thus, multiteam systems with high IFD and high vertical coordinated action were 1.6 times less likely than others to experience mission failure. These findings indicate that our results are not only statistically significant but also have tangible relevance from a practical perspective.

TABLE 3

Horizontal Coordination, Aspirational Behavior, and Multiteam System Performance

\begin{tabular}{lcc}
\hline & \multicolumn{2}{c}{ Multiteam system performance } \\
\cline { 2 - 3 } & \multicolumn{1}{c}{ Step 1 } & Step 2 \\
\hline Past performance & $14.81(2.92)^{* *}$ & $14.85(2.88)^{* *}$ \\
IFD & $-3.08(2.92)$ & $-3.61(2.87)$ \\
Horizontal coordination & & $7.50(2.87)^{* *}$ \\
Aspirational behavior & & $5.90(2.86)^{*}$ \\
R-square (adjusted) & $0.093^{* *}$ & $0.128^{* *}$ \\
R-square change & & $0.035^{* *}$ \\
\hline
\end{tabular}

Note: $n=236$ multiteam systems. Unstandardized regression coefficients are shown; standard errors are noted within parentheses.

${ }^{*} p<.05$

${ }^{* *} p<.01$

\section{DISCUSSION}

Multiteam systems are increasingly being used to accomplish a wide array of complex tasks, ranging from large-scale research and development projects to military operations and disaster relief (Goodwin et al., 2012; Hoegl et al., 2004). Although such systems have the potential to flexibly and effectively cope with challenges beyond the means of other organizational forms, research has demonstrated that they do not live up to their promise in many cases (DeChurch \& Mathieu, 2009; Donahue \& Tuohy, 2006). The present study takes important steps to address this issue. It is among the first to investigate IFD as a key predictor of multiteam system performance. In doing so, it extends previous research on the role of IFD in standalone teams and larger organizations where results have been contradictory, and it presents a unified model that reconciles these past discrepancies within a multiteam system context.

These results can advance the way scholars think about the role of IFD and, more generally, about multiteam system management. Specifically, our findings indicate that neither the positive relationships between IFD and performance reported in research on standalone teams (e.g., Bunderson \& Sutcliffe, 2002; Park et al., 2009) nor the negative performance implications of IFD reported in research on larger organizations (e.g., Buyl et al., 2011; Postrel, 2002) generalize toward multiteam systems in a straightforward manner. Rather, IFD appears to be a double-edged sword in this context. On the one hand, we found evidence for a potentially beneficial role, in that IFD can promote multiteam systems' horizontal coordination. On the other hand, our findings also point toward potential downsides, with IFD restraining systems' aspirational behavior. Thus, the performance implications of IFD in multiteam systems are more complex than previous research would suggest. It 
FIGURE 2a

\section{Conditional Indirect Effect of IFD at Higher Levels of Vertical Coordinated Action (+1.0 SD).}

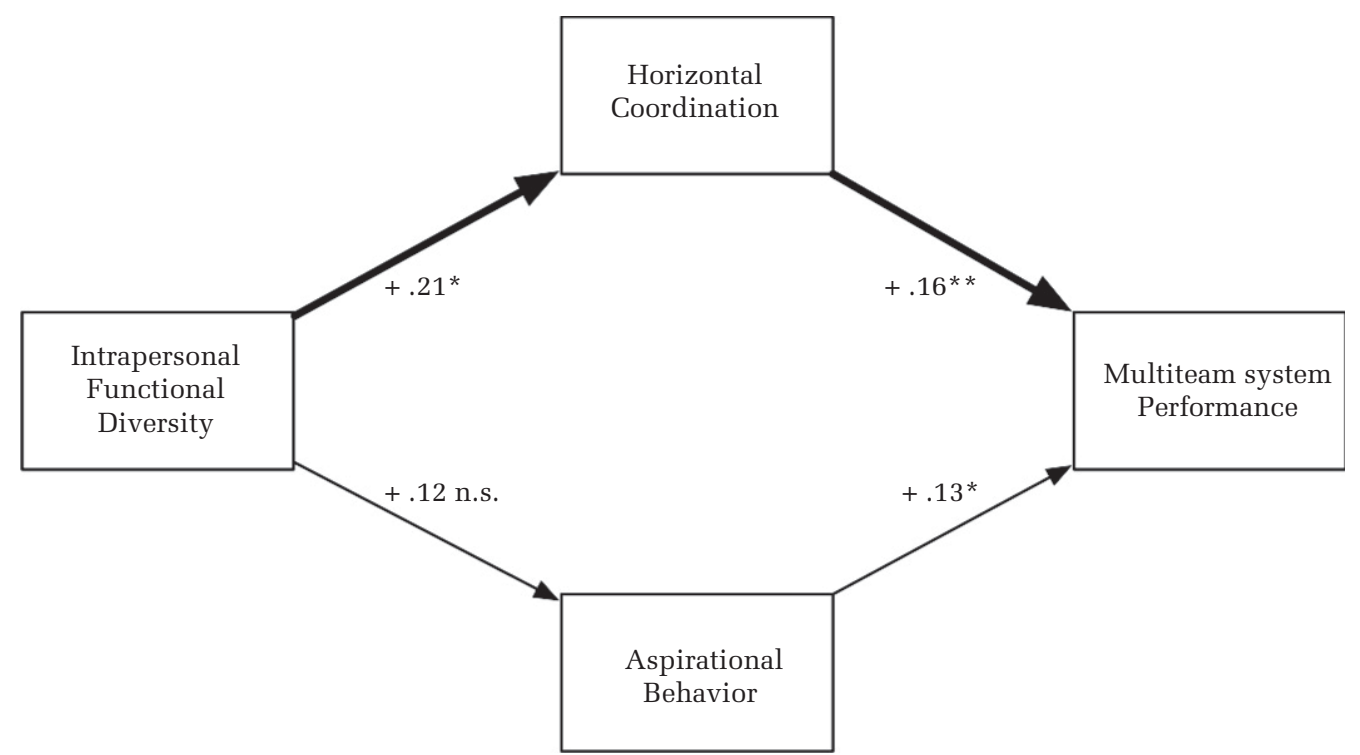

Notes: Standardized regression coefficients are shown; significant indirect paths are indicated with thick arrows.

${ }^{*} p<.05$

$* * p<.01$

appears that members with broad functional experience offer great potential for such systems but, at the same time, pose unique managerial challenges.

Our results further suggest that both the positive and the negative performance consequences of IFD are contingent on a common boundary condition. Namely, vertical coordinated action plays a crucial moderating role, enabling a multiteam system to reap IFD's benefits while mitigating associated drawbacks. Although multiteam systems are prototypically less hierarchical than traditional organizations (Davison et al., 2012; Mathieu et al., 2001), these results show that vertical coordinated action by a central team tasked with integrative leadership responsibilities is a key success factor even in this organizational form.

These findings contribute to research on multiteam systems and collaborative team structures by advancing both micro-level OB and macro-level OT perspectives on such arrangements' effectiveness and, most importantly, by illustrating how these distinct perspectives can be fruitfully integrated. Research following an OB approach, on the one hand, has emphasized IFD's role for effective coordination and task accomplishment (Ford \& Schmidt, 2000; Joshi et al., 2009). Typically, however, this literature has examined IFD within standalone teams (Bunderson \& Sutcliffe, 2002; Park et al., 2009; Rulke \& Galaskiewicz, 2000), and has consequentially neglected the larger organizational context in which teams' bottom-up potentials for coordination may unfold. Even to the extent that these studies have examined strategies for promoting IFD (e.g., personnel transfer, cross-functional job rotation) alongside contextual, top-down integration mechanisms (e.g., reward schemes, colocation [Leenders \& Wierenga, 2002; Maltz \& Kohli, 2000]), this research has considered such mechanisms as an alternative (rather than a supplement) to IFD. The present manuscript addresses this issue by illustrating the fact that IFD's effects may critically depend on formal integration teams' efforts, thus advancing OB-based theories of multiteam system functioning by embedding component teams' emergent potentials for horizontal coordination within their larger context.

Multiteam system research originating from an OT tradition, on the other hand, has discussed integration teams' importance for enabling horizontal coordination in differentiated team structures (Browning, 1998; Davison et al., 2012). Empirical studies on this issue have concluded, however, that integration teams' effectiveness often remains "questionable," emphasizing the need to more closely examine determinants of such effectiveness (Lawrence \& Lorsch, 1967: 13; see also Dewsnap \& Jobber, 2009). Addressing this ambiguity, our 
FIGURE 2b

Conditional Indirect Effect of IFD at Lower Levels of Vertical Coordinated Action (-1.0 SD).

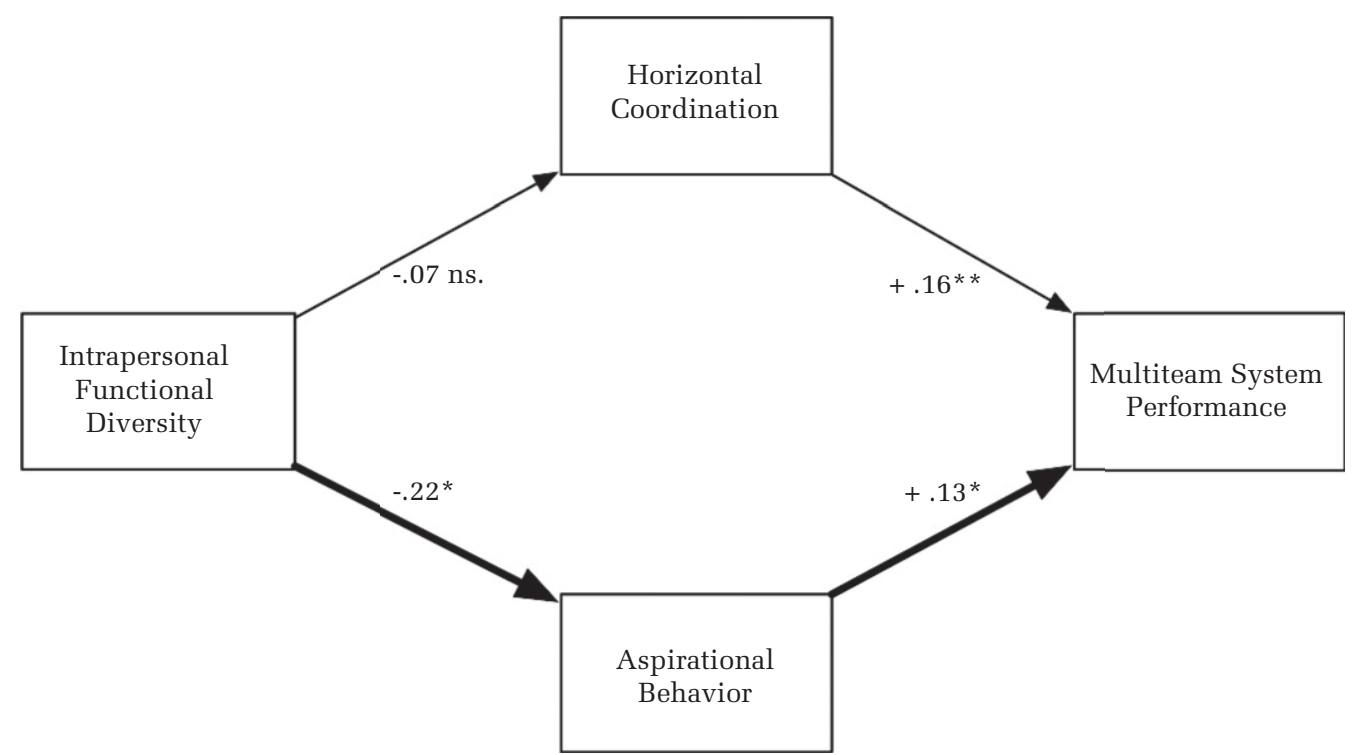

Notes: Standardized regression coefficients are shown; significant indirect paths are indicated with thick arrows.

${ }^{*} p<.05$

${ }^{* *} p<.01$

findings illustrate that an integration team's mere presence (i.e., a purely structural solution) may not be sufficient; an integration team's benefits for horizontal coordination, aspirational behavior, and multiteam system performance hinge on the degree to which this team actively aligns its activities with component teams (i.e., vertical coordinated action). In addition, our study shows that in order to fully understand vertical coordinated action's role, one needs to consider this top-down integration mechanism in conjunction with a multiteam system's bottom-up potentials for coordinated task achievement (as derived from IFD). To effectively resolve multiteam systems' performance challenges, integration teams need to actively support component teams in utilizing their capacities for horizontal coordination, while preventing the negative side effects such capacities may entail (e.g., reduced aspirational behavior).

Finally, these findings advance new insights on the functioning of multiteam systems. Multiteam system scholars have typically considered top-down guidance and bottom-up emergence of horizontal coordination as alternative, mutually exclusive strategies toward realizing collective efforts. Lanaj et al. (2013), for example, suggested that it is more effective to rely on integration teams, rather than component teams, for managing critical coordination processes. This may, however, have oversimplified the complex reality within dynamic multiteam settings (Lewis, 2000), where integrative leaders and lower-level members need to combine top-down support and bottom-up efforts in order to effectively coordinate work. By integrating OB and OT insights, the present research shows how central integration teams and decentralized component teams can mutually support coordination in a complementary way, thereby promoting multiteam system success. As such, this study advances a new approach for multiteam system theory that capitalizes on component teams' distinct capacities as well as formal integrative leaders' efforts.

\section{Limitations}

The present research has several strengths, including a large sample of multiteam systems observed in a rigorously controlled setting with a high degree of psychological realism (Berkowitz \& Donnerstein, 1982). Nevertheless, some limitations should be taken into consideration when interpreting our findings. As noted above, ethical and practical issues precluded us from manipulating IFD and randomly assigning multiteam systems to distinct conditions. Given that our model is in line with previous theoretical work that has identified IFD as a potential antecedent of multiteam systems' 
coordination and performance (e.g., Ford \& Schmidt, 2000), we have some confidence in the predicted causal directions. Nonetheless, we recognize a need for more evidence based on experimental designs with random assignment before causal inference is justified. Moreover, we did not capture multiteam systems' rationale for developing IFD. Hence, although IFD was unrelated to prior multiteam system processes and performance, we cannot ascertain participants' motivation for rotating to a different functional domain. Importantly, however, the natural emergence of IFD in the present multiteam systems appears consistent with IFD's development in many "traditional" organizations, where members can typically exert a certain degree of influence over their own functional development (e.g., by taking on a different job [Higgins, 2001; Vardi, 1980]).

Further, some real-life multiteam systems may contain more members and teams compared to the systems studied here (Goodwin et al., 2012). At the same time, multiteam systems represent an intermediate organizational form, located between large organizations or collaboration networks and standalone teams. Thus, multiteam systems comprising as few as two or three teams are not uncommon, as reflected in the definition of this type of organization (i.e., "two or more teams that interface directly and interdependently in response to environmental contingencies toward the accomplishment of collective goals"; Mathieu et al., 2001: 290). In addition, the number and size of the multiteam systems studied here compares favorably with prior experimental research (for a review, see Davison \& Hollenbeck, 2012).

With regard to our IFD measure, one might argue that the fact that participants could only change functional domains between the first and second simulation sessions limited their opportunity to develop broad functional experiences. In real-life organizations, individuals may vary more widely in this regard (e.g., de Vries, Walter, van der Vegt, \& Essens, 2014). This concern is somewhat mitigated, however, by the fact that IFD reflects a collective property at the multiteam system level. As a result, there was sufficient variation in IFD between the multiteam systems in our sample to meaningfully test the proposed relationships. Relatedly, there may be real-life instances in which low (high) IFD does not translate into deep (broad) functional knowledge to the same degree as in the present study (e.g., repetitive, routine tasks). As multiteam systems typically deal with complex and uncertain issues (Mathieu et al., 2001), however, we believe such situations will be relatively uncommon in this context.

Further, although our computerized decisionmaking simulation enabled hypotheses testing in a relatively controlled setting, it came at the cost of reduced generalizability. We tried to mitigate this concern by using actual employees (i.e., Air Force officers) for whom multiteam system performance affected career advancement. In addition, the simulation was a realistic exercise that closely resembled participants' regular work. Moreover, although this study did not follow multiteam systems over a period of years, it was not a short-term laboratory investigation of strangers that cooperated for just a few hours. Multiteam systems worked together for five consecutive weeks on different tasks (including the LDS). Nevertheless, generalization of our findings to longerterm, non-military contexts is an open question that can only be addressed through constructive replication in diverse field settings.

Other potential concerns may relate to our use of LDS computer log files to derive key measures. This measurement approach fit the present manuscript's focus on IFD's behavioral outcomes and helped us to overcome key weakness associated with more subjective, survey-based or observational instruments (e.g., recall and response bias, social desirability [Schwarz, 1999]). On the other hand, this approach prevented us from capturing fine-grained (e.g., cognitive or affective) mechanisms and micro-processes through which IFD may translate into horizontal coordination and aspirational behavior (see de Vries et al., 2014; Lanaj et al., 2013). Similarly, we were unable to depict the specific means through which integration teams enacted vertical coordinated action (e.g., through face-to-face communication, formal documents, or visual cues). Additional research employing alternative (e.g., survey- or observation-based) instruments may be useful to explore such detailed micro-mediation processes and, thus, to further understand the relationships illustrated in the present study.

Finally, this study's relatively small effect sizes may lead to concerns about our results' practical significance-although we believe the binomial effect size displays presented above alleviate such reservations to some extent. In addition, Prentice and Miller (1992: 160-161) have argued that even small effect sizes (in statistical terms) may be "impressive" when they show that "a minimal manipulation of the independent variable still accounts for some variance in the dependent variable." In the present case, we note that a relatively small development of IFD within a limited range of functional domains over a limited time frame was sufficient to shape key processes relevant for multiteam system performance. Thus, our findings reveal IFD's distinct potential (in combination with vertical 
coordinated action) to influence multiteam systems' functioning.

\section{Future Research}

Beyond addressing limitations, future research could extend our conceptual model in several important ways. For example, such research could broaden the current manuscript's focus on IFD's behavioral consequences by incorporating antecedent conditions that lead to the development of IFD. Scholars could examine, for example, whether IFD is more effective when members voluntarily choose to switch functional domains to broaden their functional knowledge, rather than being forced to rotate because they performed poorly in their original function (see Tesluk \& Jacobs, 1998).

Subsequent research could also explore task and contextual characteristics as alternative contingency factors for the relationship between IFD and multiteam system performance. IFD's positive consequences (through horizontal coordination), for example, may intensify with higher interteam task interdependence, because multiteam systems may then place stronger demands on members' capacities for aligning activities across component teams (Joshi et al., 2009). Highly uncertain and complex environments, on the other hand, may place a premium on functionally narrow members with deep knowledge for substantive, high-impact tasks, rather than functionally broad members with more superficial perspectives. Hence, IFD's negative performance implications (through reduced aspirational behavior) may be particularly salient in such environments. Additional research could build on these notions to further complete our understanding of IFD's role in multiteam settings.

In addition, it may be interesting to extend our conceptual model by investigating antecedents of vertical coordinated action. Clearly, integration teams in the present study differed markedly in the extent to which they engaged in this type of behavior. Some of these teams, for example, proactively communicated their system-wide insights toward component teams (an example of high vertical coordinated action), whereas others withdrew themselves from component teams and enforced their own, independent perspectives on task completion within the multiteam system (an example of low vertical coordinated action; see also Davison et al., 2012). Such differences may, for example, stem from variability in integration teams' task and goal orientations (Lawrence \& Lorsch, 1967) or integration team members' dominance and assertiveness
(Haleblian \& Finkelstein, 1993). Empirically examining these ideas may advance our understanding of the micro-foundations of vertical coordinated action as a key aspect of multiteam system effectiveness.

\section{Practical Implications}

The challenge of effectively coordinating multiple specialized teams involved in joint tasks has long troubled management practice (Mathieu et al., 2001; Smith et al., 1995). Despite repeated efforts to improve such coordination, for example, Donahue and Tuohy (2006) concluded that the emergency response operations following hurricane Andrew in 1992, the Oklahoma City bombing in 1995, the 9/11 terrorist attacks in 2001, and Hurricane Katrina in 2005 all suffered from duplicate and conflicting efforts among involved teams and organizations. Similar problems have been documented within the logistics and health care fields, with scholars noting "there seems to be a general lack of managerial ability to integrate and coordinate the intricate network of business relationships" (Kanda \& Deshmukh, 2008: 317) and "despite their efforts to collaborate, professionals are lost in translation across healthcare boundaries" (Kerosuo, 2010: 372).

The present study addresses this problem and has important implications for the management of multiteam systems (as well as traditional organizations designed according to multiteam system principles; Millikin, Hom, \& Manz, 2010). Based on our results, for example, it appears possible to improve horizontal coordination and multiteam system performance by selecting members with broad functional experiences or by promoting such experiences through training opportunities and appropriate assignments. Importantly, several off-the-shelf solutions are available for enhancing IFD, including job rotation and personnel transfer schemes (Griffin \& Hauser, 1996; Leenders \& Wierenga, 2002), career development trajectories (Raskas \& Hambrick, 1992), and cross-training strategies (Cannon-Bowers et al., 1998; Marks et al., 2002). By increasing IFD, multiteam system leaders may enable component teams to bridge language, thought-world, and goal differences that may otherwise prove detrimental.

By itself, selecting or training functionally broad members is unlikely to guarantee high multiteam system performance. Our results suggest that without effective integration team support (through vertical coordinated action), horizontal coordination may be too complex and burdensome even for multiteam systems with high IFD. In fact, IFD may even 
diminish multiteam system performance in such situations by lowering a system's aspirational behavior. Again, multiteam system leaders may rely on well-developed interventions to promote vertical coordinated action, thus realizing IFD's potentials and circumventing its downsides. "Frame-of-reference" training, for example, may provide component and integration teams with a standardized language that enables efficient coordination across a multiteam system's hierarchical layers (Firth et al., 2014: 814). Similarly, "strategizing” or "coordinating” interventions (i.e., training integrative leaders in providing component teams with feedback on their effectiveness in the multiteam system) may improve integration teams' capacity for vertical coordinated action (DeChurch \& Marks, 2006: 312). By combining high IFD with effective vertical coordination, multiteam systems may be able to live up to their full potential and succeed in meeting the challenges of the environments in which they operate.

Finally, limits associated with time and training budgets imply trade-offs associated with developing IFD, and the present study informs organizational leaders' decision making in this regard. If a multiteam system is vertically well-coordinated, in particular, substantial performance advantages may be realized by developing members' IFD. In contrast, if a system is lacking effective vertical coordination, increasing IFD may entail considerable performance risks. Management could, then, prioritize the development of vertical coordinated action, before devoting resources to strengthening IFD.

\section{REFERENCES}

Becker, T. E. 2005. Potential problems in the statistical control of variables in organizational research: A qualitative analysis with recommendations. Organizational Research Methods, 8: 274-289.

Berkowitz, L., \& Donnerstein, E. 1982. External validity is more than skin deep: Some answers to criticisms of laboratory experiments. The American Psychologist, 37: 245-257.

Brown, C. V. 1999. Horizontal mechanisms under differing IS organization contexts. Management Information Systems Quarterly, 23: 421-454.

Browning, T. R. 1998. Integrative mechanisms for multiteam integration: Findings from five case studies. Systems Engineering, 1: 95-112.

Bunderson, J. S., \& Sutcliffe, K. M. 2002. Comparing alternative conceptualizations of functional diversity in management teams: Process and performance effects. Academy of Management Journal, 45: 875-893.
Burke, L. A., \& Steensma, H. K. 1998. Towards a model for relating executive career experiences and firm performance. Journal of Managerial Issues, 10: 86-102.

Buyl, T., Boone, C., Hendriks, W., \& Matthyssens, P. 2011. Top management team functional diversity and firm performance: The moderating role of CEO characteristics. Journal of Management Studies, 48: 151-177.

Cannella, A. A., Park, J. H., \& Lee, H. U. 2008. Top management team functional background diversity and firm performance: Examining the roles of team member colocation and environmental uncertainty. Academy of Management Journal, 51: 768-784.

Cannon-Bowers, J. A., Salas, E., Blickensderfer, E., \& Bowers, C. A. 1998. The impact of cross-training and workload on team functioning: A replication and extension of initial findings. Human Factors, 40: 92-101.

Cramton, C. D. 2001. The mutual knowledge problem and its consequences for dispersed collaboration. Organization Science, 12: 346-371.

Crichton, M., \& Flin, R. 2004. Identifying and training nontechnical skills of nuclear emergency response teams. Annals of Nuclear Energy, 31: 1317-1330.

Davison, R. B., \& Hollenbeck, J. R. 2012. Boundary spanning in the domain of multi-team systems. In S. J. Zaccaro, M. A. Marks, \& L. A. DeChurch (Eds.), Multiteam systems: An organization form for dynamic and complex environments: $323-362$. New York, NY: Routledge.

Davison, R. B., Hollenbeck, J. R., Barnes, C. M., Sleesman, D. J., \& Ilgen, D. R. 2012. Coordinated action in multiteam systems. The Journal of Applied Psychology, 97: 808-824.

DeChurch, L. A., \& Marks, M. A. 2006. Leadership in multiteam systems. The Journal of Applied Psychology, 91: 311-329.

DeChurch, L. A., \& Mathieu, J.E. 2009. Thinking in terms of multiteam systems. In E. Salas, G. F. Goodwin, \& C. S. Burke (Eds.), Team effectiveness in complex organizations: Cross-disciplinary perspectives and approaches: 267-292. New York: Routledge.

DeChurch, L. A., \& Zaccaro, S. J. 2010. Perspective: Teams won't solve this problem. Human Factors, 52: 329-334.

de Vries, T. A., Walter, F., van der Vegt, G. S., \& Essens, P. J. M. D. 2014. Antecedents of individuals' interteam coordination: Broad functional experiences as a mixed blessing. Academy of Management Journal, 57: 1334-1359.

Dewsnap, B., \& Jobber, D. 2009. An exploratory study of sales-marketing integrative devices. European Journal of Marketing, 43: 985-1007. 
Donahue, A. K., \& Tuohy, R. V. 2006. Lessons we don't learn: A study of the lessons of disasters, why we repeat them, and how we can learn them. Homeland Security Affairs, 2: 1-28.

Edwards, J. R., \& Lambert, L. S. 2007. Methods for integrating moderation and mediation: A general analytical framework using moderated path analysis. Psychological Methods, 12: 1-22.

Ellis, A. P. J., \& Pearsall, M. J. 2011. Reducing the negative effects of stress in teams through cross-training: A job demands-resources model. Group Dynamics, 15: 16-31.

Entin, E. E., \& Serfaty, D. 1999. Adaptive team coordination. Human Factors, 41: 312-325.

Espinosa, J., Slaughter, S., Kraut, R., \& Herbsleb, J. 2007. Team knowledge and coordination in geographically distributed software development. Journal of Management Information Systems, 24: 135-169.

Faraj, S., \& Yan, A. 2009. Boundary work in knowledge teams. The Journal of Applied Psychology, 94: 604-617.

Firth, B., Hollenbeck, J. R., Miles, J., Ilgen, D. R., \& Barnes, C. M. 2014. Same page, different books: Extending representational gaps theory to enhance performance in multiteam systems. Academy of Management Journal, 58: 813-835.

Ford, J. K., \& Schmidt, A. M. 2000. Emergency response training: Strategies for enhancing real-world performance. Journal of Hazardous Materials, 75: 195-215.

Galbraith, J. R. 1994. Competing with flexible lateral organizations. New York, NY: Addison-Wesley.

Gioia, D. A., \& Pitre, E. 1990. Multiparadigm perspectives on theory building. Academy of Management Review, 15: 584-602.

Goodwin, G. F., Essens, P. J. M. D., \& Smith, D. 2012. Multi-team systems in the public sector. In S. J. Zaccaro, M. A. Marks, \& L. A. DeChurch (Eds.), Multiteam systems: An organization form for dynamic and complex environments: 53-78. New York, NY: Routledge.

Griffin, A., \& Hauser, J. R. 1996. Integrating R\&D and marketing: A review and analysis of the literature. Journal of Product Innovation Management, 13: 191-215.

Gulati, R. 1998. Alliances and networks. Strategic Management Journal, 19: 293-317.

Haleblian, J., \& Finkelstein, S. 1993. Top management size, CEO dominance, and firm performance: The moderating roles of environmental turbulence and discretion. Academy of Management Journal, 36: 844-863.

Hatvany, N., \& Pucik, V. 1981. An integrated management system: Lessons from the Japanese experience. Academy of Management Review, 6: 469-480.
Higgins, M. C. 2001. Changing careers: The effects of social context. Journal of Organizational Behavior, 22: 595-618.

Hoegl, M., Weinkauf, K., \& Gemuenden, H. G. 2004. Interteam coordination, project commitment, and teamwork in multiteam R\&D projects: A longitudinal study. Organization Science, 15: 38-55.

Holloway, S., \& Parmigiani, A. 2014. Friends and profits don't mix: The performance implications of repeated partnerships. Academy of Management Journal, 59: 460-478.

House, R., Rousseau, D. M., \& Thomas-Hunt, M. 1995. The meso paradigm: A framework for the integration of micro and macro organizational behavior. Research in Organizational Behavior, 17: 71-114.

Huxham, C., \& Vangen, S. 2000. Leadership in the shaping and implementation of collaboration agendas: How things happen in a (not quite) joined-up world. Academy of Management Journal, 43: 1159-1175.

Jans, N., \& Frazer-Jans, J. 2004. Career development, job rotation, and professional performance. Armed Forces and Society, 30: 255-277.

Joshi, A., Pandey, N., \& Han, G. H. 2009. Bracketing team boundary spanning: An examination of task-based, team-level, and contextual antecedents. Journal of Organizational Behavior, 30: 731-759.

Kanda, A. K., \& Deshmukh, S. G. 2008. Supply chain coordination: Perspectives, empirical studies and research directions. International Journal of Production Economics, 115: 316-335.

Kerosuo, H. 2010. Lost in translation: A patient-centred experience of unintegrated care. International Journal of Public Sector Management, 23: 372-380.

Klein, G., \& Pierce, L. 2001. Adaptive teams. Fairborn, OH: Klein Associates.

Knight, D., Durham, C. C., \& Locke, E. A. 2001. The relationship of team goals, incentives, and efficacy to strategic risk, tactical implementation, and performance. Academy of Management Journal, 44: 326-338.

Kotha, R., George, G., \& Srikanth, K. 2013. Bridging the mutual knowledge gap: Coordination and the commercialization of university science. Academy of Management Journal, 56: 498-524.

Kozlowski, S. W. J., \& Klein, K. J. 2000. A multilevel approach to theory and research in organizations: Contextual, temporal, and emergent processes. In K. J. Klein \& S. W. J. Kozlowski (Eds.), Multilevel theory, research, and methods in organizations: Foundations, extensions, and new directions: 3-90. San Francisco, CA: Jossey Bass.

Kusunoki, K., \& Numagami, T. 1998. Interfunctional transfers of engineers in Japan: Empirical findings and implications for cross-functional integration. IEEE 
Transactions on Engineering Management, 45: 250-262.

Lanaj, K., Hollenbeck, J. R., Ilgen, D. R., Barnes, C. M., \& Harmon, S. J. 2013. The double-edged sword of decentralized planning in multi-team systems. Academy of Management Journal, 56: 735-757.

Lawrence, P. R., \& Lorsch, J. W. 1967. Differentiation and integration in complex organizations. Administrative Science Quarterly, 12: 1-47.

Leenders, M. A. A. M., \& Wierenga, B. 2002. The effectiveness of different mechanisms for integrating marketing and R\&D. Journal of Product Innovation Management, 19: 305-317.

Lewis, M. W. 2000. Exploring paradox: Towards a more comprehensive guide. Academy of Management Review, 25: 760-776.

Maltz, E., \& Kohli, A. K. 2000. Reducing marketing's conflict with other functions: The differential effects of integrating mechanisms. Journal of the Academy of Marketing Science, 28: 479-492.

Marks, M. A., DeChurch, L. A., Mathieu, J. E., Panzer, F. J., \& Alonso, A. 2005. Teamwork in multiteam systems. The Journal of Applied Psychology, 90: 964-971.

Marks, M. A., Sabella, M. J., Burke, C. S., \& Zaccaro, S. J. 2002. The impact of cross-training on team effectiveness. The Journal of Applied Psychology, 87: 3-13.

Marrone, J. A. 2010. Team boundary spanning: A multilevel review of past research and proposals for the future. Journal of Management, 36: 911-940.

Mathieu, J. E., Marks, M. A., \& Zaccaro, S. J. 2001. Multiteam systems. In N. Anderson, D. S. Ones, H. K. Sinangil, \& C. Viswesvaran (Eds.), Handbook of industrial, work and organizational psychology: 289-313. London, U.K.: Sage.

Millikin, J. P., Hom, P. W., \& Manz, C. C. 2010. Selfmanagement competencies in self-managing teams: Their impact on multi-team system productivity. The Leadership Quarterly, 21: 687-702.

Park, M. H., Lim, J. W., \& Birnbaum-More, P. H. 2009. The effect of multiknowledge individuals on performance in crossfunctional new product development teams. Journal of Product Innovation Management, 26: 86-96.

Parry, M. E., \& Song, X. M. 1993. Determinants of R\&Dmarketing integration in high-tech Japanese firms. Journal of Product Innovation Management, 10: 4-22.

Postrel, S. 2002. Islands of shared knowledge: Specialization and mutual understanding in problem-solving teams. Organization Science, 13: 303-320.

Prentice, D. A., \& Miller, D. T. 1992. When small effects are impressive. Psychological Bulletin, 112: 160-164.

Puranam, P., Raveendran, M., \& Knudsen, T. 2012. Organization design: The epistemic interdependence perspective. Academy of Management Review, 37: 419-440.

Raskas, D. F., \& Hambrick, D. C. 1992. Multifunctional managerial development: A framework for evaluating the options. Organizational Dynamics, 21: 5-17.

Reuer, J., \& Devarakonda, S. 2015. Mechanisms of hybrid governance: Administrative committees in nonequity alliances. Academy of Management Journal, 59: 510-533.

Rosenthal, R., \& Rubin, D. B. 1982. A simple, general purpose display of magnitude of experimental effect. Journal of Educational Psychology, 74: 166-169.

Rulke, D. L., \& Galaskiewicz, J. 2000. Distribution of knowledge, group network structure, and group performance. Management Science, 46: 612-625.

Schulze, W. S., Lubatkin, M. H., \& Dino, R. N. 2003. Exploring the agency consequences of ownership dispersion among the directors of private family firms. Academy of Management Journal, 46: 179-194.

Schwarz, N. 1999. Self-reports. The American Psychologist, 54: 93-105.

Sherman, J. D., \& Keller, R. T. 2011. Suboptimal assessment of interunit task interdependence: Modes of integration and information processing for coordination performance. Organization Science, 22: 245-261.

Sinha, K. K., \& Van de Ven, A. H. 2005. Designing work within and between organizations. Organization Science, 16: 389-408.

Smith, K. G., Carroll, S. J., \& Ashford, S. J. 1995. Intraand interorganizational cooperation: Toward a research agenda. Academy of Management Journal, 38: 7-23.

Srikanth, K., \& Puranam, P. 2011. Integrating distributed work: Comparing task design, communication, and tacit coordination mechanisms. Strategic Management Journal, 875: 849-875.

Tesluk, P.E., \& Jacobs, R. R. 1998. Toward an integrated model of work experience. Personnel Psychology, 51:321-355.

Vardi, Y. 1980. Organizational career mobility: An integrative model. Academy of Management Review, 5: 341-355.

Zaccaro, S. J., Marks, M. A., \& DeChurch, L. A. 2012. Multiteam systems: An introduction. In S. J. Zaccaro, M. A. Marks, \& L. A. DeChurch (Eds.), Multi-team systems: An organization form for dynamic and complex environments: 3-32. New York, NY: Routledge.

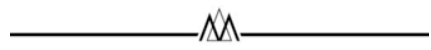

Thomas A. de Vries (thom.de.vries@rug.nl) is an assistant professor at the Faculty of Economics and Business at the University of Groningen. He received his $\mathrm{PhD}$ in business administration from the University of Groningen. He conducts 
research on boundary spanning, interteam processes, resilience, and multiteam systems.

John R. Hollenbeck (jrh@bus.msu.edu) holds the positions of University Distinguished Professor at Michigan State University and Eli Broad Professor of Management at the Eli Broad Graduate School of Business Administration. Dr. Hollenbeck received his PhD in Management from New York University in 1984.

Robert B. Davison (rbd@ku.edu) is an assistant professor of organizational behavior at the University of Kansas School of Business. He earned his $\mathrm{PhD}$ in organizational behavior and human resource management at Michigan State University, and conducts research in the areas of compact organizations, integrative leadership and organizational entitativity.
Frank Walter (frank.walter@wirtschaft.uni-giessen.de) is professor of organization and human resource management at the University of Giessen. He received his PhD from the University of St. Gallen. His research interests include team processes, leadership, emotions in the workplace, and new forms of team-based collaboration.

Gerben S. van der Vegt (g.s.van.der.vegt@rug.nl) is a full professor of organizational behavior at the Faculty of Economics and Business at the University of Groningen, where he received his $\mathrm{PhD}$ in social and organizational psychology. His research interests include effective team design, and power, status, and leadership in organizations.

$M$ 
Copyright of Academy of Management Journal is the property of Academy of Management and its content may not be copied or emailed to multiple sites or posted to a listserv without the copyright holder's express written permission. However, users may print, download, or email articles for individual use. 